\title{
HOW DEEP IS YOUR APPROACH TO LEARN? A STUDY WITH UNDERGRADUATE PSYCHOLOGY STUDENTS.
}

\author{
Francesca Chiesi \\ University of Florence, Italy \\ francesca.chiesi@unifi.it
}

\begin{abstract}
Statistical skills are deemed important for psychology students as a prerequisite to learn psychometrics. Thus, the aim of the current study was to identify the learning approach that is more likely to result in better retention of statistics prerequisites to learn psychometrics, and to highlight the individual characteristics of students who adopt it. Data were collected from a sample of students enrolled in a psychometrics course and who had previously passed a statistics exam. At the beginning of the course, several scales were administered to measure statistics self-confidence and attitudes, learning approaches, learning conceptions and teaching preferences, and statistics knowledge. Results showed that knowledge was positively associated to a deep approach to learn, and several individual differences were observed between students who decided to use vs not to use this approach. These findings contribute to current state of knowledge on statistics education and they suggest areas of intervention.
\end{abstract}

\section{INTRODUCTION}

Statistical skills are deemed important for psychology students because they serve as a prerequisite to learn theory and technique of psychological measurement, i.e. psychometrics. For this reason, most undergraduate psychology majors require to take an introductory statistics course followed by a psychometrics course. Unfortunately, psychology students encounter many difficulties in passing statistics exams and, among the various possible explanations, the role of non- cognitive factors has been investigated (e.g., Chiesi \& Primi, 2010, 2017; Emmioglu \& Capa-Aydin, 2012; Hood, Creed, \& Neumann, 2012; Tempelaar, van Der Loeff \& Gijselaers, 2007). These studies suggest that psychology students tend to have negative feelings, they show low self-confidence and interest, they fail to understand the relevance of the discipline in their future professional activities, and, as a consequence, they are less likely to engage in fruitful learning behaviors. Broadly speaking, it was stressed the role of attitudes and learning approaches.

Attitudes toward statistics can be defined as a disposition to respond favourably or unfavourably to objects, situations, or people related to statistics learning (Schau, Stevens, Dauphinee \& del Vecchio, 1995). It is a multi-dimensional construct that consists of affective (i.e., students' positive and negative feelings about statistics), cognitive (i.e., beliefs about the discipline and the skills requested to learn statistics, or self-efficacy), and behavioural (i.e., students' interest and effort spent to learn statistics) components.

The approaches to learning paradigm is one of the most widely used frameworks for understanding how students go about learning in higher education (Tight, 2003). It states that the quality of student learning outcomes is influenced by students' approaches to learning, defined as surface, deep, and strategic. Specifically, a surface approach is characterized by a lack of personal engagement in the learning process. As such, concepts and subjects are learned in an unreflective and unrelated manner, and learning consists of rote-memorising without understanding or misunderstanding important concepts (Ramsden, 2003). In contrast, a deep approach to learning is characterized by a personal commitment to learning. Students adopting this approach aim to comprehend what they are learning and approach critically the arguments, they evaluate whether concepts and contents are justified by evidence, and try to associate them to their prior knowledge. As such, learning is more likely to result in retention and application of knowledge (Biggs, 2003; Ramsden, 2003). Finally, students' strategic approach is characterized by a strong achievement motivation and is tailored on the assessment demands. This approach describes well-organised study methods finalized to obtain high grades (Struyven, Dochy, Janssens \& Gielen, 2006).

Starting from this premise, the aim of the current study was twofold. Since some introductory statistics topics are deemed necessary for understanding theory and technique of psychological measurement, the first aim was to identify the learning approach that is more likely to result in better retention of the statistics prerequisites to learn psychometrics. The second aim was to highlight the 
individual characteristics of students who spontaneously adopt it. Specifically, we investigated attitudes toward the discipline as well as self-efficacy, conceptions about learning, and teaching preferences.

\section{METHODS}

\section{Participants}

Data were collected from 200 second year psychology students enrolled in a psychometrics course (named Theory and Technique of Psychological Testing) at the University of Florence in Italy. The course was compulsory and shaving passed a statistics exam was a requirement. Participants' age ranged from 20 to 48 with a mean age of 21.10 years $(S D=3.05)$, and most of them were women $(87 \%)$. This percentage reflects the gender distribution of the population of psychology students in Italy All students participated on a voluntary basis after they were given information about the general aim of the investigation.

\section{Measures and Procedure}

Students were presented a questionnaire consisting of the following scales.

- A revised version of the Approaches and Study Skills Inventory for Students (ASSIST, Tait, Entwistle, \& McCune, 1998). The scale was developed in a previous study (Chiesi et al., 2016) and it consists of three parts (Section A, Section B, and Section C). Section B is the core part of the scale because it is focused on the learning approaches. It contains 32 items, and respondents indicate the degree of their agreement with each statement using a five-point Likert scale $(1=$ disagree and 5= agree). The items are combined into three sub-scales: the Surface scale (12 items) is about lack of purpose, unrelated memorizing, and syllabus-boundness (e.g., "I find I have to concentrate on just memorizing a good deal of what I have to learn"), the Deep scale (12 items) is about seeking meaning, relating ideas, and use of evidence (e.g., "I usually set out to understand for myself the meaning of what we have to learn"), the Strategic scale (8 items) is about organized studying and time management, (e.g., "I manage to find conditions for studying which allow me to get on with my work easily").

Section A and Section C survey students' overall conceptions of learning and preferences for different type of teaching. Section A consists of 6 items combined in two sub-scales: Learning as Reproducing and Learning as Transforming. In detail, three items are about learning as reproducing knowledge (e.g., "Building up knowledge by acquiring fact and information"), and three items are about learning as personal understanding and development (e.g., "Understanding new material for yourself"). Respondents indicated how close their own way of thinking was with each statement using a five-point Likert scale $(1=$ very different and $5=$ very close). Section $\mathrm{C}$ consists of 8 items combined in two sub-scales: Transmitting Information and Supporting Understanding. In detail, four items are about teaching focused basically in transmitting information (e.g., "Courses in which it's made very clear just which book we have to read"), and four items are about teaching that encourage understanding (e.g., "Courses where we're encouraged to read around the subject a lot for yourself"). Respondents indicated their degree of preference using a five-point Likert scale ( $1=$ definitely dislike and $5=$ definitely like).

- The 36-item Survey of Attitudes Toward Statistics (SATS-36; Schau, 2003) provides a multidimensional measure of attitude that includes the perception of statistics in itself and as part of the degree program, as well as affective and cognitive components. The SATS-36 includes the same items of the SATS-28 (Schau et al., 1995; Italian version: Chiesi \& Primi, 2009) and eight items designed to assess two additional components: Interest and Effort. In detail, it assesses the following six components: Affect (6 items) measures positive and negative feelings concerning statistics (e.g. "I will feel insecure when I have to do statistics problems" or "I like statistics"); Cognitive Competence ( 6 items) measures students' attitudes about their intellectual knowledge and skills when applied to statistics (e.g. "I can learn statistics" or "I make a lot of math errors in statistics"); Value (9 items) measures attitudes about the usefulness, relevance, and worth of statistics in personal and professional life (e.g. "Statistics is worthless" or "Statistical skills will make me more employable"); Difficulty (7 items) measures students' attitudes about the difficulty of statistics as a subject (e.g. "Statistics formulas are easy to understand" or "Statistics is a complicated subject"); Interest (4 items) measures students' level of individual interest in statistics 
(e.g. "I am interested in using statistics"); Effort (4 items) measures the amount of work the student expends to learn statistics ("I plan to work hard in my statistics course"). Respondents indicated their degree of preference using a seven-point Likert ( $1=$ totally disagree and $7=$ totally agree).

- The Current Statistics Self-Efficacy scale (CSSE, Finney \& Schraw, 2003; Italian version: Chiesi, Primi, \& Galli, 2007) assesses individuals' confidence in their ability to complete specific statistics-related tasks. The CSSE contains 14 Likert-type items asking students to express their level of confidence in successfully solving statistics problems (e.g., "Distinguish between the information given by the three measures of central tendency", "Identify a scale of measurement for a variable") using a five-point scale ( $1=$ not at all and $5=$ totally).

- The Introductory Statistics Inventory (ISI, Chiorri, Piattino, Primi, Chiesi \& Galli, 2009) consists of multiple-choice items (one correct out of four choices) on introductory statistics topics. Ten questions were selected including issues that serve as a prerequisite for the psychometrics course (e.g., descriptive indices, $z$-values, correlation, and regression).

The questionnaire was filled online during the first day of the course. It was introduced briefly to the students and instructions for completion were given. In particular, students were requested to fill the ASSIST - Section B referring at the learning approach they used for the statistics exam they took before attending the Theory and Technique of Psychological Testing course. The scales were presented in the following order: SATS, CSSE, ASSIST, and ISI. The time needed to complete the questionnaire ranged from 15 to 25 minutes.

\section{RESULTS AND DISCUSSION}

Learning approach and statistics learning. Pearson's correlations were computed to examine the relationships between learning approaches and statistics learning (Table 1). Correlations were positive and moderate between knowledge of statistics basics and the Deep approach, and negative and weak with the Surface approach. No correlation was observed between knowledge and the Strategic approach. As expected, a deep approach is more likely to lead to consolidated knowledge and long-term retention, while rote-learning, the main characteristic of the surface approach, leads to short-term retention. These relationships are moderate probably because there are other variables that affect long-term retention. Indeed, since students had followed different statistic courses, dissimilarities in teaching methods, course requirements, and final examination might have an effect on their actual knowledge over the approach they adopted to learn. Finally, the strategic approach was unrelated with students' statistics knowledge probably because the uses of tailored strategies to maximize achievement not always yield to long term knowledge.

Table 1: Correlations among approaches to learn and statistics knowledge.

\begin{tabular}{llcccc}
\hline & $M$ & $S D$ & 1 & 2 & 3 \\
\hline 1 Deep Approach & 3.63 & 0.59 & -- & & \\
2 Surface Approach & 2.43 & 0.58 & $-.36^{* *}$ & -- & \\
3 Strategic Approach & 3.50 & 0.78 & $.36^{* *}$ & -.34 & -- \\
4 Statistics Knowledge & 5.45 & 2.03 & $.27^{* *}$ & $-.14^{*}$ & -.08
\end{tabular}

Individual characteristics of students who differ in the deep approach. Two groups were created on the $35^{\text {th }}$ and $65^{\text {th }}$ percentile (3.33 and 3.38, respectively) of the Deep approach score to compare low Deep $(N=72)$ and high Deep $(N=78)$ students on attitudes toward statistics, statistics self-confidence, learning conceptions, and teaching preferences (see Table 2 for descriptives). With the exception of Affect $t(148)=0.48, p=.63)$ and Difficulty $(t(148)=-0.53, p=.59)$, differences were observed for the Cognitive Competence $(t(148)=-2.86, p<.01, d=-.47)$, Value $(t(148)=-3.88, p<$ $.001, d=-.63)$, Effort $(t(148)=-3.79, p<.001, d=-.62)$, and Interest $(t(148)=-3.90, p<.001, d=-$ .64). Specifically, whereas the two groups equally judge statistics in term of difficulty and affect, higher deep approach students were more confident about their own capabilities, they believe that statistics is relevant in their personal and professional life, they are interested in the curses and they 
put effort in learning. Consistently, students with higher deep approach were much more confident than low deep approach students about their ability to solve statistics tasks $(t(148)=-6.82, p<.001, d$ $=-1.12)$. Finally, we observed differences in Learning as Reproducing $(t(148)=-5.25, p<.001, d=-$ $.89)$, Learning as Transforming $(t(148)=-6.14, p<.001, d=-1.00)$, Transmitting Information $(t(148)$ $=-2.15, p<.05, d=-.35)$, and Supporting Understanding $(t(148)=-6.80, p<.001, d=-1.12)$. Surprisingly, while differences in Learning as Transforming and Supporting Understanding were expected, high deep approach students scored higher in all these learning conceptions and teaching preferences. One possible explanation is that they believe important also learning as reproducing and teaching as transmitting information because of the course requirements. As such, they take into account also these aspects when learning statistics and attending statistics lectures. Moreover, the difference in Transmitting Information is moderate $(d=-.35)$, while a strong difference $(d=-1.12)$ is observed for teaching as supporting understanding.

Table 2. Means and standard deviations of attitudes toward statistics, self-efficacy, learning conceptions, and teaching preferences for students differentiated by deep learning approach.

\begin{tabular}{llcccc}
\hline & & Low Deep & \multicolumn{2}{c}{ High Deep } \\
\hline Variable & Test and sub-scales & $M$ & $S D$ & $M$ & $S D$ \\
\hline \multirow{3}{*}{ Attitudes toward } & SATS - Affect & 4.05 & 1.33 & 4.16 & 1.50 \\
statistics & SATS - Difficulty & 3.54 & 0.77 & 3.47 & 0.81 \\
& SATS - Effort & 5.43 & 1.19 & 6.07 & 0.86 \\
& SATS - Interest & 3.68 & 1.20 & 4.59 & 1.59 \\
& SATS - Value & 4.83 & 0.93 & 5.41 & 0.90 \\
& SATS - Cognitive Competence & 4.92 & 1.10 & 5.42 & 1.06 \\
\hline Self-Efficacy & CSSE & 2.34 & 0.70 & 3.09 & 0.64 \\
\hline \multirow{3}{*}{ Learning } & ASSIST Section A - & & & & \\
conceptions and & Learning as Reproducing & 3.80 & 0.60 & 4.29 & 0.54 \\
teaching & ASSIST Section A - & & & & \\
preferences & Learning as Transforming & 3.85 & 0.72 & 4.49 & 0.55 \\
\cline { 2 - 6 } & ASSIST Section C - & & & & \\
& Transmitting Information & 3.67 & 0.72 & 3.92 & 0.74 \\
\cline { 2 - 6 } & ASSIST Section C - & & & & \\
& Supporting Understanding & 3.33 & 0.70 & 4.05 & 0.57 \\
\hline
\end{tabular}

Note: SATS= Survey of Attitudes Toward Statistics; CSSE= Current Statistics Self-Efficacy scale; ASSIST= Approaches and Study Skills Inventory for Students.

\section{CONCLUSION}

To the best of our knowledge, before the retention of statistical concepts have not been investigated taking into account learning approaches to statistics and individual differences in students' attitudes, self-confidence, learning conceptions, and teaching preferences. As such, these findings might contribute to the current state of knowledge on factors that impact on statistics education, and might help in developing didactical intervention strategies. Indeed, approaches to learning are not intrinsic characteristics of students (Lucas \& Mladenovic, 2004; Ramsden, 2003) but they are sensitive to the context in which the learning occurs, i.e., learning approaches are affected by students' perceptions of the learning situation and are influenced by the demands of particular learning environments (Rhem, 1995). Consequently, the fact that psychology students, i.e., students progressing towards a degree quite different from statistics, have to pass a statistics course might have an influence on the learning approach they adopt. Presumably, their goal is just to pass the exam and then forget it. So they are likely to adopt a surface approach characterized by unreflective studying and rote-learning or they might opt for a strategic approach focused on the specific course demands. Nonetheless, the current results suggest that only a deep approach promotes a consolidated and longterm retention of statistics concepts. Thus, because they need statistics knowledge to progress in their future educational career, it is of fundamental importance to help students in choosing this approach.

In achieving this goal, it is useful identifying characteristics of students who spontaneously adopt it, such as individual differences in attitudes, self-confidence, conceptions about learning and 
teaching preferences. The current findings suggest that intervention strategies should support positive changes in attitudes toward the discipline and, in particular, they should contrast negative ones. Indeed, students who hold negative attitudes toward statistics aren't willing to put in the effort needed to learn deeply statistics. One possible teaching strategy might be to stress the links with the future profession making clear the need to acquire statistical concepts for psychology students, e.g., explaining the importance of being able to manage some statistics concept to use tests for psychological assessment. Specifically, to promote a deep approach, it might be useful presenting real examples of statistics applied to psychology and to explain how statistics procedures can be helpful in this domain, to discuss expected and unexpected findings, to develop different hypothesis from the results of data analyses, and so on. In that way, we should promote the adoption of a deep approach to learn because students become aware of the relevance of statistics for psychologists.

Finally, some limitations of the present study need to be acknowledged and amended in future investigations. Indeed, the current results are limited by the specific sample characteristics (i.e., Italian psychology students) and by the choice of some self-report scales. Although these limitations, the current study offers new insights on factors that impact on statistics education and they suggest areas of intervention.

\section{REFERENCES}

Biggs, J. (2003). Teaching for quality learning at University (2nd edition). Buckingham: SRHE and Open University Press.

Chiesi, F., Primi, C. \& Galli, S. (2007). Un contributo all'adattamento della versione italiana della scala Current Statistics Self-Efficacy (CSSE) [A Contribution to the adaptation of the Italian version of the Current Statistics Self-Efficacy scale (CSSE)]. Congresso Nazionale AIP - Sezione di Psicologia Sperimentale.

Chiesi, F., \& Primi, C. (2009). Assessing statistics attitudes among college students: Psychometric properties of the Italian version of the Survey of Attitudes Toward Statistics (SATS). Learning and Individual Differences, 19(2), 309-313.

Chiesi, F., \& Primi, C. (2010). Cognitive and non-cognitive factors related to students' statistics achievement. Statistics Education Research Journal, 9(1), 6-26.

Chiesi, F., Primi, C., Bilgin, A. A., Lopez, M. V., Fabrizio, M. C., Gozlu, S., \& Tuan, N. M. (2016). Measuring university students' approaches to learning statistics: An invariance study. Journal of Psychoeducational Assessment, 34(3), 256-268.

Chiesi, F., \& Primi, C. (2017). Attitudes and learning approaches: modelling a pathway to achievement in statistics. Proceedings of the 61th ISI World Statistics Congress, Marrakech, Morocco.

Chiorri, C., Piattino, S., Primi, C., Chiesi, F., \& Galli, S. (2009, August). Why Psychology Students don't Like Statistics? MathPsych, Amsterdam.

Emmioglu, E., \& Capa-Aydin, Y. (2012). Attitudes and achievement in statistics: A meta-analysis study. Statistics Education Research Journal, 11(2), 95-102.

Finney, S. J., \& Schraw, G. (2003). Self-efficacy beliefs in college statistics courses. Contemporary Educational Psychology, 28(2), 161-186.

Hood, M., Creed, P. A., \& Neumann, D. L. (2012). Using the expectancy value model of motivation to understand the relationship between student attitudes and achievement in statistics. Statistics Education Research Journal, 11(2), 72-85.

Lucas, U., \& Mladenovic, R. (2004). Approaches to learning in accounting education. Accounting Education, 13, 399-407.

Ramsden, P. (2003). Learning to teach in higher education (2nd edition). London: Routledge Falmer.

Rhem, J. (1995). Deep/surface approaches to learning: an introduction. The National Teaching and Learning Forum, 5, 1-5.

Schau, C. (2003). Survey of Attitudes Toward Statistics (SATS-36). [Online: http://evaluationandstatistics.com/]

Schau, C., Stevens, J., Dauphinee, T. L., \& Del Vecchio, A. (1995). The development and validation of the Survey of Attitudes Toward Statistics. Educational and Psychological Measurement, 55(5), $868-875$. 
Struyven, K., Dochy, F., Janssens, S., \& Gielen, S. (2006). On the dynamics of students' approaches to learning: The effects of the teaching/learning environment. Learning and Instruction, 16(4), 279-294.

Tight, M. (2003). Researching higher education. Maidenhead: McGraw Hill.

Tait, H., Entwistle, N., \& McCune, V. (1998). ASSIST: A re-conceptualisation of the approaches to studying inventory." In C. Rust (Ed.) Improving student learning: Improving students as learners (pp. 262-271). Oxford: The Oxford Centre for Staff and Learning Development.

Tempelaar, D. T., van Der Loeff, S. S., \& Gijselaers, W. H. (2007). A structural equation model analysing the relationship of students' attitudes toward statistics, prior reasoning abilities and course performance. Statistics Education Research Journal, 6(2), 78-102. 